\title{
EPMA of K and Na in Two Types of Aged NOx Catalysts for Diesel Engines
}

\author{
Jon Hangas, Giovanni Cavataio, and Yisun Cheng
}

Ford Motor Company, MD3182, PO Box 2053 Dearborn, MI 48121.

Diesel engines have higher fuel economy than gasoline engines, but produce more nitrous oxide (NOx) air pollution because they run with a high air:fuel ratio. Two competing technologies for NOx removal are Lean NOx Traps (LNT), and urea Selective Catalytic Reduction (SCR). Electron microprobe analysis (EPMA) in this study will document the distribution and possible effects of $\mathrm{K}$ and $\mathrm{Na}$ on these catalysts in a set of hydrothermally aged LNTs, and in a vehicle-aged urea SCR. K was intentionally added to the LNT to improve NOx conversion. In the SCR the alkalis are undesirable contaminants.

In the $\mathrm{LNT} \mathrm{BaCO}_{3}$ adsorbs NOx on its surface while the engine is run lean, and then during short rich cycles the NOx is released and reduced by Pt present in catalyst. $\mathrm{K}_{2} \mathrm{O}$ was intentionally added to improve conversion during high temperature cycles which are needed for cleaning soot from a diesel particulate filter or de-sulfating the LNT. Urea SCR uses small amounts of urea sprayed into the exhaust stream in front of a transition metal doped zeolite catalyst. The urea reacts with the NOx on the catalyst to produce $\mathrm{N}_{2}$ and $\mathrm{H}_{2} \mathrm{O}$. In this catalyst alkalis are undesirable because they can potentially cause ion exchange of the transition metal catalyst and deactivate the SCR.

The pieces of cores from catalyst bricks were impregnated with epoxy, and polished with grit sizes down to $1 \mu \mathrm{m}$ diamond using alcohol (LNT) or kerosene (SCR) to avoid alkali loss. After carbon coating the cores were examined in a JEOL8200 EPMA. X-ray maps were processed using routines written for ImageJ to make semi-quantitative maps. ZAF analyses were obtained but in the highly porous catalytic washcoats they must be considered semi-quantitative.

The LNT formulation was experimental and similar to a typical three-way catalyst (TWC) for automotive use in that it had a zirconia rich outer washcoat layer (bright layer in the upper right of the backscattered electron images (BSE) in figure 1) with traces of Rh, and an alumina rich inner layer with small amounts of ceria, zirconia, and traces of Pt. K was uniformly distributed in the fresh material, with some occasional precipitation of $\mathrm{KCO}_{3}$ in shrinkage cracks. In hydrothermal lab aging at $1000^{\circ} \mathrm{C}$ for $16 \mathrm{hr}$ significant diffusion of $\mathrm{K}$ and $\mathrm{Na}$ into the cordierite has occurred. ZAF point analyses measured $14 \mathrm{wt} \% \mathrm{~K}_{2} \mathrm{O}$ and $1 \mathrm{wt} \% \mathrm{Na}_{2} \mathrm{O}$ in a layer a few microns thick on the surface of the cordierite, consistent an alkali-rich glass which could weaken the cordierite substrate. Diffusion into the cordierite occurs as low as $700^{\circ} \mathrm{C}$ in other samples.

The SCR catalyst consists of two 6-inch long bricks in sequence, and was from a vehicle driven 50k miles on the road. Trace levels of $\mathrm{K}_{2} \mathrm{O}$ and $\mathrm{Na}_{2} \mathrm{O}$ are present along the length of the catalyst system (Figure 2). The wt\% totals in the ZAF analysis were only 52-58wt\%. In spite of the poor totals it is still possible to obtain relative composition differences in each cross section by acquiring more than 30 points in each washcoat layer. The middle of the first SCR brick consistently had the lowest $\mathrm{Na}$ and $\mathrm{K}$ content. In each cross section the inner washcoat had less alkali than the outer washcoat, suggesting the origin of $\mathrm{K}$ and $\mathrm{Na}$ was from the use of biodiesel, road salt, or other source during vehicle use. Neither $\mathrm{K}$ nor $\mathrm{Na}$ were present in previously examined fresh bricks of this formulation. 
In testing catalytic activity only the first inch from the inlet has lost activity. Based on the fairly uniform $\mathrm{K}$ and $\mathrm{Na}$ concentrations in Figure 2, the alkalis may not be at fault. However, alkali contamination may have occurred in one short event early in the drive cycle, deposited heavily at the inlet, and thereafter migrated downstream with use. Testing is in progress measuring the performance of a series of SCRs that have been doped with varying amounts of $\mathrm{K}_{2} \mathrm{O}$ and then labaged at $800^{\circ} \mathrm{C}$ for 8 hours. The ability of these SCRs to convert NOx decreases with increasing K and $\mathrm{Na}$ content, suggesting that $\mathrm{K}$ replaces some the transition metal in the zeolite by ion exchange.

Acknowledgements: The authors wish to thank Mark Jagner for XRF results.

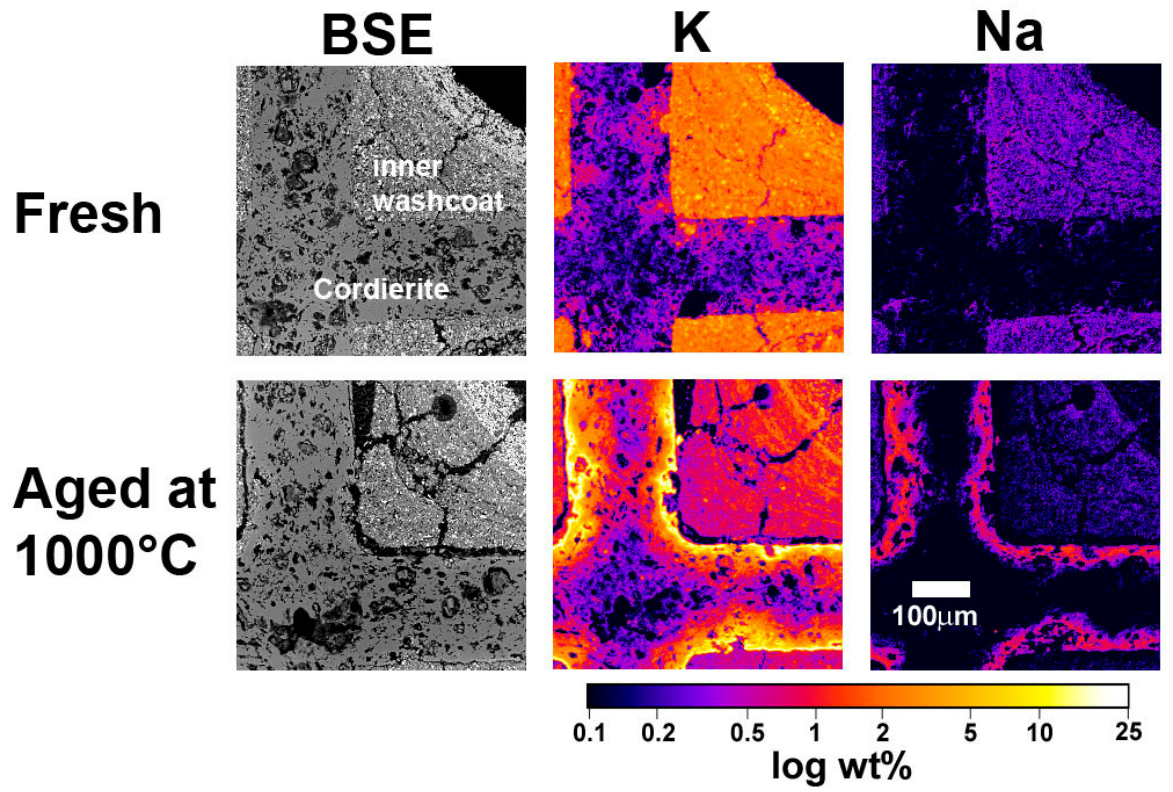

Figure 1. K and Na are uniformly distributed in the washcoat of the fresh LNT and appear in trace amounts in the cordierite, while after aging at $1000^{\circ} \mathrm{C}$ alkali diffusion from the washcoat to the cordierite has occurred, with a glass forming on the surface of the cordierite.

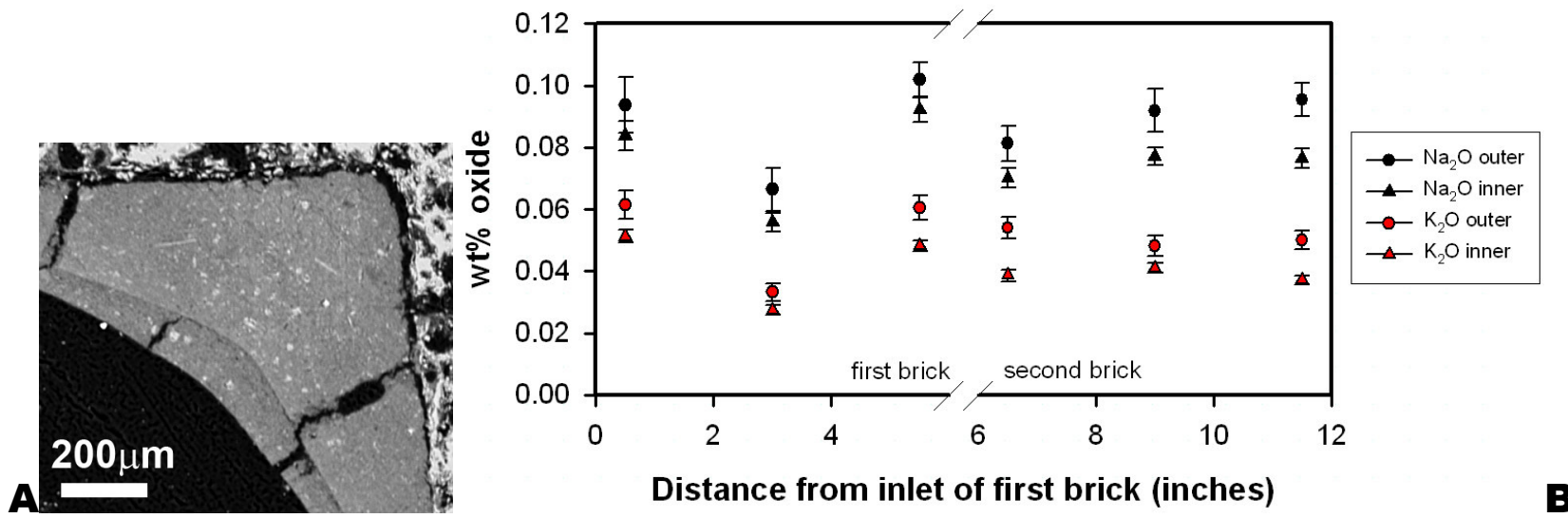

Figure 2. A) BSE image of the two layer washcoat at 5.5 inches from the inlet. B) Distribution of $\mathrm{Na}_{2} \mathrm{O}$ and $\mathrm{K}_{2} \mathrm{O}$ in measured in cross sections along the length of the SCR system. The outer layer consistently had higher $\mathrm{Na}_{2} \mathrm{O}$ and $\mathrm{K}_{2} \mathrm{O}$ content. Error bars are the $95 \%$ confidence level of the mean. 